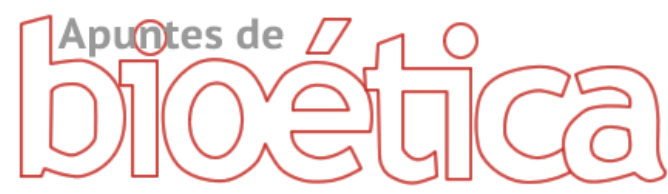

https://doi.org/10.35383/apuntes.v2i2.284

\title{
La castidad como virtud, para la comprensión del sentido de la sexualidad humana
}

\author{
Jesús Simón Cuyate Reque ${ }^{1}$
}

INFORMACIÓN DEL ARTÍCULO RESUMEN

\section{Historia del artículo:}

Recibido el 20 de setiembre de 2019

Aceptado el 27 de diciembre de 2019

\section{Palabras claves:}

Castidad

Sexualidad

Virtud

Amor humano
En el presente artículo se analiza la problemática sobre la distorsión del verdadero significado y sentido de la sexualidad, por lo que, para dar solución a esta situación, se plantea la siguiente propuesta: la virtud de la castidad, es el medio para la comprensión del sentido de la sexualidad humana, detallándose un marco conceptual sobre, en qué consiste la sexualidad, la castidad $y$, fundamentando el por qué nos permite una profundización en el significado de nuestra sexualidad. Concluyendo que, la vivencia de la virtud de la castidad permite comprender el sentido de la sexualidad orientada hacia el amor, desde la integridad personal y desde el modo de ser varón o mujer.

The virtue of chastity, for the understanding of the meaning of human sexuality

\section{ABSTRACT}

\section{Keywords:}

Chastity

Sexuality

Virtue

Human love
The present essay found the problem about the distortion of the true meaning of sexuality, so that, in order to solve this situation, it raises the thesis, of being the virtue of chastity, the means for understanding the meaning of sexuality human, detailing a conceptual framework on what sexuality, chastity consists of and justifying why it allows us to deepen the meaning of our sexuality.

Concluding that the experience of the virtue of chastity allows us to understand the sense of sexuality towards love, from personal integrity and from the way of being male or female 


\section{Introducción}

Frente a las nuevas formas de educación sexual promulgadas a nivel mundial encontramos problemas que desvirtúan el verdadero sentido de la sexualidad, entre los cuales se resalta: el uso de preservativos, métodos abortivos, pastillas contraceptivas, promoción de la masturbación como una forma sana de descubrimiento de la sexualidad, la defensa de la homosexualidad, la proliferación de la promiscuidad, la fecundación in vitro como derecho que calma el anhelo de ser padres, la búsqueda de la legalización del aborto como derecho femenino, etc.

En realidad, ¿Esto es comprender la sexualidad? ¿Esto es educarla? Ni siquiera es una aproximación a la belleza que encierra este don otorgado al ser humano.

Empero, no es visto así por entidades mundiales que dicen orientar. Planned Parenhood (2019), por ejemplo, desarrolla programas para informar a los jóvenes en cuanto su sexualidad, sin embargo, solo se enfoca en los métodos anticonceptivos y abortivos como la alternativa para una vivencia libre de la sexualidad.

Entre otro de los programas internacionales también se encuentra el Centro de Promoción y Defensa de los Derechos Sexuales y Reproductivos - Promsex (2019) que difunde evitar un embarazo no deseado como responsabilidad frente a la sexualidad.

Pero, iser responsables realmente con la sexualidad es únicamente rechazar la llegada de un nuevo ser, o incluso asesinarlo si ya estuviese concebido?

El problema ahonda y se especifica aún más en el Perú, el Fondo de Población de las Naciones Unidas - UNFPA (2019) denota la existencia de fondos económicos dedicados a una difusión de la sexualidad reducida solo a sexo, con la problemática ya mencionada anteriormente.

Además, los índices de iniciación de relaciones sexuales en adolescentes según el INEI (2015) presenta a jovencitas que ni si quiera cumplen aún los 15 años de edad así como, los embarazos en jovencitas menores de 20 años, el uso de métodos anticonceptivos, etc.

Por tanto, ¿se está comprendiendo realmente lo que es la sexualidad? ¿Estos medios y programas realmente permiten la vivencia de la sexualidad tal cual está llamada a ser?

Y con todo ello, ¿dónde podríamos encontrar el fundamento de la sexualidad si no es en el hombre mismo?

Urge, así entonces, la necesidad de redescubrir la esencia de la sexualidad desde la naturaleza misma del hombre. Por lo que se cuestiona:

¿Con qué podemos comprender el sentido de la sexualidad humana desde la naturaleza del hombre mismo?

\section{Propuesta}

El ser humano es capaz de alcanzar aquello que se denomina virtud. En el presente trabajo, se pretende resaltar especialmente una relacionada con la sexualidad que posibilita el conocimiento profundo de ésta, tal virtud es: la castidad.

Por lo que, se lanza la siguiente tesis:

La castidad es la virtud que entrena en el amor, permitiendo la comprensión profunda de nuestra sexualidad desde nuestra capacidad de amar en alma y cuerpo. 


\section{Fundamentación Teórica}

\section{La sexualidad es bellísima}

Primero que quede claro que la sexualidad es bellísima, frente a concepciones reduccionistas que no reflejan su maravilla, siendo que hay más en esta hermosa facultad, que el hombre se encuentra llamado a descubrir y vivir.

Por eso, siguiendo a Loring (1998), depuremos primero de la sexualidad dos concepciones erróneas en general: una, que la sexualidad es mala, y dos, que es únicamente para la complacencia del ego.

Este autor presenta dos actitudes equivocadas frente a la sexualidad: la del puritano y la del hedonista moderno. La primera, considera impura y negativa a la sexualidad, a consecuencia del olvido de la dignidad del cuerpo humano; y la segunda, aspira únicamente al placer, a la autosatisfacción y que, por ello, en este camino, jamás conoce el amor verdadero, solo amoríos.

Ahora, pasemos a descubrir porque la sexualidad es bella entonces

\section{Porque la persona es bella...}

La persona es un ser excelente: es única, irrepetible, va más allá de un "qué", es un quién, un "alguien"; de ahí que tiene un nombre $y$, de ahí que responde a la pregunta ¿quién eres? (Yepes y Aranguren, 2003). Es un misterio maravilloso, por lo que todo de ella, es una maravilla, incluido su ser sexuado.

Para reafirmar esto, Melendo (2007) realiza un tratado sobre la belleza de la sexualidad partiendo desde la persona como un ser llamado al amor y, por tanto, la sexualidad implicada a este llamado. Así explica que:
La persona, ser singularísimo, único y que posee dignidad, está llamada a la entrega de sí, a la donación, por tanto, su sexualidad también se perfeccionará con ello: iEstamos hechos para la entrega y nuestra sexualidad también!

La heroicidad frente al mundo actual consiste en recordar con hechos y palabras, a las demás personas, que estamos hechos para dar, evitando así el egoísmo por el placer sexual y todo modo de utilización de la persona.

El filósofo personalista Wojtyla (1979), también respalda el planteamiento, afirmando que, el hombre con toda su naturaleza, alma y cuerpo, tiende al amor, del cual es sujeto y objeto.

Por lo tanto, si la sexualidad es bella porque la persona lo es, y si la persona está llamada a la donación, la belleza de la sexualidad se encontrará en la entrega pues ahí ha de encontrar su perfeccionamiento y sentido

Y es justo que la sexualidad, por ser única e incomparable y distinta a los animales, es humana, es personal (Melendo, 2007).

Hasta aquí, una primera premisa deducida sería: la belleza de la sexualidad radica en el ser para el amor de la persona, por lo que mi ser sexuado está orientado para amar.

Solo partiendo desde este punto, es posible exigir para nuestro ser algo que nos perfeccione en el amor, como lo hará la castidad, cuando se detalle más adelante.

\section{¿Por qué más es bella?}

\section{La sexualidad es integral.}

La sexualidad implica toda la persona, afirma Santa María (1999), pues no se limita a 
una función de órganos sexuales ni a una relación de cuerpos.

Se trata de un elemento propio de nuestra identidad, que viene determinada por un conjunto de componentes biológicos y espirituales (Lucas, 2005).

Por tanto, sexualidad y sexo no son lo mismo, aunque muchos medios de comunicación nos presentan una parte sesgada de la sexualidad, es necesario actualmente una profundización antropológica que revele la verdad sobre la grandeza de la sexualidad.

Para mayor contemplación de la complejidad de ésta, Fernández (2001) propone que es en sí misma una perfección que implica por lo menos, siete niveles, los cuales se describen a continuación:

Para el autor, la sexualidad es:

Cromosómica-genética. Viene dada por los cromosomas constituyentes del sexo, como masculino o femenino, siendo el elemento más original y primario.

Morfológica-genital. Aquí sucede la diferenciación específica de ambos sexos, abarcando desde las diferencias somáticas, hasta la morfología orgánica, puesto que, es evidente que el cuerpo del varón es distinto al de la mujer.

Cognoscitiva. Esta dimensión le otorga otro nivel, superando a los animales, porque la sexualidad implica el uso de nuestra inteligencia, nuestro discernimiento y de la capacidad de conocer, justo para saber elegir. Somos capaces de razonar, pensar, reflexionar sobre el desarrollo de mi sexualidad, evitando que suceda simplemente como si se tratase solo de un mero instinto.

Voluntaria-Responsable. Porque el ejercicio de la sexualidad responde a un querer de la voluntad. Esto es lo que permite al hombre ser verdaderamente libre con respecto a su sexualidad; no se trata de un "soy libre con mi sexo y hago lo que se me da la gana", sino, "soy libre, por lo tanto, responsable y no soy preso de mis pasiones"

Afectiva. Porque a través de ésta, el ser humano manifiesta sentimientos, atracción entre varón y mujer y demás realidades psicológicas englobadas y transmitidas a través del afecto.

Vaya realidad que es capaz no solo de configurar al hombre como varón o mujer, sino que les da la oportunidad de expresar afecto, sentimientos, a través del alma y cuerpo.

Placentera. Puesto que, en la relación de varón y mujer, sucede la "fiesta del amor", experiencia conyugal donde en la intimidad aparece el placer sexual como un componente no buscado en sí mismo. El dato curioso en este nivel es que: inicia desde el orgasmo fisiológico (dimensión genital), incluyendo la vida afectiva (dimensión afectiva), para terminar, significando un amor responsable (cognoscitiva y volitiva), cuyo verdadero sentido se da al fundirse cuerpos y almas de quienes se aman en un "para siempre".

Y pensar que, mientras que la sociedad quiere imponer y plantear el placer como fin egoísta; entendido bien aparece como consecuencia de la unión de amor de los esposos.

Procreadora. Porque el amor entre un varón y una mujer, reclama fecundidad, la generación de la prole, ya que cuando los esposos se unen, desean al hijo.

Con todo esto, podemos ver a la sexualidad de manera integral: cuerpo, alma y afectividad. Esto significa que implica y abraza todo nuestro ser, exige todo de nosotros, porque está en todo lo que nosotros somos. 
Hasta aquí, se puede llegar a otra premisa deducida: la belleza de la sexualidad está en su integridad personal, ya que implica a todo el ser personal y sus distintas dimensiones.

Se podría seguir hablando de las maravillas de la sexualidad, y sería interminable el presente ensayo, pero para esta investigación, se ha querido resaltar esta última:

\section{La sexualidad nos tipifica como varón y mujer.}

Castilla (2004), indica que lo propio del varón es salir de sí, mientras que lo propio de la mujer es la acogida, ambos se complementan y su unidad es capaz de alcanzar la fecundidad, y es pues, gracias a la sexualidad que sucede este complemento diferenciado.

Por su parte, Castillo (2003) de las diferentes características entre varón y mujer, resalta que: para ellos, es más fácil el cambio de "página" y el ser parciales; es casi imposible que realicen muchas actividades al mismo tiempo, pues lo propio es ir por partes, además de entenderse mejor en el trabajo con objetos, con las cosas. Mientras que la mujer, posee un centro reunitivo, capaz de guardar mucho en su interior y además de relacionar y realizar muchas actividades al mismo tiempo. Esto debido a su llamado a la maternidad, inclinándose así, al trato con personas. Además, en ella suele ser más natural el educar.

Presentar la importancia de las diferencias entre varón y mujer permite observar que la naturaleza sexual de ambos exige una forma de amor distinta, y un modo específico de vivir la sexualidad.

\section{Castidad: ¿Qué es?}

Ahora sí, se describe la propuesta para la comprensión del sentido de la sexualidad: la castidad.
Proviene del latín "castus", cuyo significado es "puro". Por tanto, pureza y castidad se pueden tomar como sinónimos. Así entonces, la castidad es la virtud que busca mantener puro al amor, protegerlo del egoísmo, o de los impulsos que distancien de lo valiosa que es la otra persona. No se trata de una obstinada represión. (Daum, 2013)

Lejos de lo que muchos medios de comunicación quieren hacer pensar, la castidad no se centra en lo negativo, no es prohibitiva. Ya que, si afirmábamos anteriormente que la sexualidad es maravillosa, entonces la castidad confirma el valor de esta.

Se trata de un sí, del cual surgen los no; nos aclara el filósofo:

Con mucha frecuencia se entiende a la castidad como un freno ciego a la sensualidad y los mismos impulsos carnales, que rechaza los valores del cuerpo y del subconsciente donde esperan para explotar (...) al contrario es un "sí" del que en seguida siguen los "no" (...) la esencia de la castidad consiste en no dejarse distanciar por el valor de la persona y en realzar a su nivel toda reacción ante los valores del cuerpo y sexo. (Wojtyla, 1979, p. 189)

Esta virtud coloca la mirada de quien ama, en el valor de la persona amada.

Es decir, amar de forma tal, que la castidad se convierte en la afirmación a tres grandes realidades:

- Sí a la persona en su dignidad. Porque le quiero como un "alguien" y respetarle me lleva a decir no a los impulsos sensuales ciegos.

- Sí a la belleza de la sexualidad. Comprendiéndola en su bondad, 
orientándola hacia la afirmación del amor.

- Sí, a mi ser hecho para amar. Puesto que amo en alma, cuerpo y afectividad y oriento para que todo mi ser exprese, incluyendo mi naturaleza sexuada, amor autentico.

En tal sentido, Veronese en García (2002) reafirma lo expuesto señalando que, la castidad resulta de la decisión del hombre, un compromiso de permanecer en la integridad.

$Y$ es aquí, donde empezamos a comprender el sentido de la sexualidad, gracias a la castidad. Como esta virtud exige perfeccionamiento en el amor, específicamente desde la tendencia sexual, entonces, al ser castos, orientamos la sexualidad hacia su finalidad: el amor mismo.

Perfeccionamiento tal, que llega entonces gracias a un sí permanente, maduro y comprometido:

La castidad - no simple continencia, sino afirmación decidida de una voluntad enamorada - es una virtud que mantiene la juventud del amor en cualquier estado de vida (Escrivá, citado en Melendo y Millán, 2008, p. 108)

Por lo tanto, en cuanto qué significa castidad, se indica que es la afirmación de la sexualidad desde su bondad, desde su belleza, desde la confirmación como valiosa.

¿Por qué la castidad nos permite una comprensión profundad de la sexualidad?

\section{Porque nos exige un entrenamiento.}

Si la castidad solo fuera una idea, entonces no generaría cambios en la vida real, si se le deja solo como valor sin llevarla a la práctica, entonces tampoco se alcanzaría una experiencia de vivir auténticamente la sexualidad.

Por eso, la propuesta es que la castidad se viva como virtud.

Las virtudes son cualidades que permanecen en el alma. Aristóteles reserva para ellas el término "hexis", que significa "hábito", aquello no espontáneo (Rodríguez, 2001). Es decir, el hombre realiza repetidamente aquello que es bueno, para adquirirlo, para que se forme en él un hábito.

Esto permite conocer mejor el sentido de la sexualidad, porque, mientras que al inicio del texto se exponía teóricamente sobre la belleza de la sexualidad, con la castidad vivida, se haría un hábito afirmar, comprometidamente esa bondad y belleza todos los días, ya que no hay mejor forma de profundizar en el sentido de la sexualidad, que en la práctica misma

Esta práctica es capaz de perfeccionar además de la sexualidad en el amor, a todo el ser humano de sobremanera. Tomás de Aquino, citado por Pieper (2003) señala que la virtud es "ultimum potentiae", es decir, lo máximo a lo que el hombre puede aspirar, la perfección de las potencias humanas tanto en lo natural como sobrenatural.

Vista así la castidad, permitiría comprender la sexualidad, además de su finalidad humana, su teleología sobrenatural, es decir, responder al "para qué" Dios la ha entregado como don al hombre.

Finalizando este apartado, San Agustín citado por Melendo y Millán (2007, p. 108) define Virtud como "ordo amoris": "aquello que permite que el amor nazca, crezca, se desarrolle, alcance su madurez y de frutos" 
Por tanto, castidad, es la virtud, que entrena en el amor.

Se trata de un entrenamiento, de un obrar consecutivamente, donde algunas veces se alcanzan las metas y otras no, siendo conscientes de nuestras debilidades y fortalezas, porque el objetivo es aprender a amar, y orientar la sexualidad hacia el amor. Puesto que, como veíamos: solo el amor otorga a las personas felicidad superior al de las cosas pasajeras, pues penetra en nuestra vida (Hildebrand, 1998)

En palabras simples, la castidad, nos entrena para ser felices, porque nuestra felicidad consiste en amar.

Te entrena en fidelidad a tu futura esposa, te ejercita en el dominio y conocimiento personal para que puedas entregarte a otra persona, permitiendo amar de un modo más profundo (Daum, 2013)

La sexualidad, en consecuencia, es comprendida de una mejor forma: se perfecciona en el amor, es posible entrenarse en amar, perfeccionándola, y cuánto más perfeccionemos nuestra sexualidad, más felices.

Ahora, a continuación, cabe resaltar que la dimensión de autodominio que posee la castidad, redescubre a la facultad sexual como personal y sobre todo libre.

\section{Es necesario, poseernos para amar}

El Consejo Pontificio para la Familia (1997, p. 28) cuando se refiere a la castidad, señala que: "es la afirmación gozosa de quien sabe vivir el don de sí. Esto supone que la persona haya aprendido a descubrir a los otros, a relacionarse con ellos respetando su dignidad en la diversidad".
Queda claro entonces que, la castidad tiene carácter de don, de entrega, de generosidad, de dar.

Sin embargo, ipuede alguien dar aquello que no posee? Se ha hablado del amor de entrega, de la orientación de la sexualidad hacia la generosidad, pero ipuede entregar su sexualidad, aquel que aún no es dueño de la misma?

La respuesta lógica es no. Por ello, es necesario que las personas sean dueñas de sí, de su ser sexuado, para poder entregarlo.

Castillo (2003) esclarece lo mencionado de esta forma: lo más fundamental en el amor, la raíz profunda, es la voluntad de donarse, y para ello es necesario poseerse, solo damos lo que tenemos, si nos poseemos, entonces nos podemos entregar.

Aquello, abre la oportunidad de comprender a la sexualidad en un recto sentido de posesión, de autodominio, de potestad sobre esta.

El sentido de la sexualidad, gracias a la vivencia de la castidad como autodominio, revela la dimensión volitiva, cognoscitiva y libre de la sexualidad. En otras palabras: la persona ya es tal, y aun así, necesita auto poseerse para perfeccionar su entrega. Asimismo, su sexualidad ya es dada, sin dejar su naturaleza sexuada otorgada y permanente, necesita poseerla para poder entregarla, para perfeccionarla.

Finalmente, la virtud de la castidad toma en cuenta a la sexualidad en cuanto a su diferenciación en ser varón y ser mujer. 
La castidad exige, amar según la tipificación sexual: como persona femenina o como persona masculina

Santa María (1999) en su libro "Saber amar con el cuerpo", relata:

Primero, que la castidad es amar en cuerpo y alma. Segundo, que la sexualidad está en toda la persona. $Y$ tercero, que varón y mujer, gracias a la sexualidad, aman diferente, que inclusive el cuerpo de cada uno está hecho o para ser padre o ser madre, alcanzando el carácter sexual hasta características espirituales de cada modo de ser.

Por tanto, la virtud de la castidad pretende también, tomar atención a las peculiaridades de cada tipificación sexual. Así, se comprende el sentido de particularidad propio de la sexualidad. Puesto que, varón y mujer son iguales en dignidad y distintos en modos de ser específicos.

Del mismo modo, en cuanto a la pureza, las mujeres, cuya sexualidad suele ser más discreta y difusa, pasan situaciones distintas al varón, cuya sexualidad suele ser más exterior y abrupta (Leonard 2003) Será por ello que el pudor exigido a ambos, requiera cierta peculiaridad en las mujeres y en los varones.

Entonces, ¿Qué comprende el hombre en este punto, habituándose a la castidad?

Que el sentido de la misma, es amar incluso, de manera particular, además de amar como persona en su integridad (cuerpo-almapsique); amar como mujer o como varón en su especificidad sexual.

\section{Conclusiones}

Luego de lo expuesto, planteamos las siguientes conclusiones
$>$ La sexualidad humana es personal, integral, total y destinada a perfeccionarse en el amor.

> La castidades una virtud que entrena en amar integralmente (cuerpo-almaafectividad) a la persona, por lo que orienta la sexualidad hacia el amor.

$>$ La virtud de la castidad permite comprender en la práctica misma el sentido de la sexualidad: su teleología hacia la donación, la necesidad por parte de la persona de poseerse en su ser sexuado para donarse luego.

$>$ La virtud de la castidad permite comprender el sentido de la sexualidad hacia el amor, desde un modo de ser específico: persona masculina o persona femenina.

\section{Bibliografía}

Centro de Promoción y Desarrollo de los Derechos Sexuales y Reproductivos (2019). Página oficial, extraído de https://promsex.org/

Castilla, B. (2004). Persona femenina, persona masculina. Madrid: Ediciones Rialp.

Castillo, G. (2003). Educación de la afectividad. Piura: Universidad de Piura.

Consejo Pontificio para la Familia (1997). Sexualidad humana: verdad y significado. Orientaciones educativas en familia. (9na ed.) Madrid: Ediciones Palabra.

Daum, J. (2013). Sexualidad y Castidad. Para los jóvenes que quieren ser hombres de verdad. Arequipa: Universidad Católica de San Pablo. 
Fernández, A. (2001). Teología Moral II: Moral de la persona y la familia. (3ra ed.) Burgos: Facultad de Teología.

Fondo de Población de las Naciones Unidas UNFPA (2019) Página oficial, extraído de https://peru.unfpa.org/es

García, V. (2002). Educación de la Sexualidad. (2da ed.) Madrid: Ediciones Rialp, S.A.

Hildebrand, D. (1998). La esencia del amor. Pamplona: Ediciones de la Universidad de Navarra.

INEI (2015). Los adolescentes y su comportamiento reproductivo 2013. Extraído de https://www.inei.gob.pe/media/MenuRec ursivo/publicaciones_digitales/Est/Lib1199 /libro.pdf

Leonard, A. (2003). La Moral sexual explicada para jóvenes. (5ta ed.) Madrid: Ediciones Palabra.

Loring, J. (1998). Para salvarte. España: EDIBESA.

Lucas, R. (2005). Antropología y Problemas Bioéticos. Madrid: Biblioteca de Autores Cristianos.
Melendo, T. (2007). La Belleza de la Sexualidad. Navarra: Ediciones Internacionales Universitarias, S.A.

Melendo, T. y Millán, L. (2008). La Chispa del amor: cómo entender $y$ enriquecer el amor. México: Editorial Trillas.

Planned Parenthood (2019) Página Oficial. extraído de https://www.plannedparenthood.org/

Rodríguez, L. (2001). Ética General. (4ta ed.) Madrid: Biblioteca de Autores Cristianos.

Yepes, R. y Aranguren, J. (2003). Fundamentos de Antropología: un ideal a la excelencia humana. (6ta ed.) España: Eunsa.

Wojtyla, K. (1979). Amor y Responsabilidad. (2da ed.) Madrid: Editorial Razón y Fe.

Santa María, G. (1999) Saber Amar con el Cuerpo: ecología sexual. (4ta ed.) Madrid: Ediciones Palabra, S.A.

Pieper, J. (2003). Las Virtudes Fundamentales. (8va ed.) Madrid: Ediciones Rialp. 